\title{
Assessment of Vegetation Cover Degradation Using Remote Sensing and GIS Techniques along Sudanese Red Sea Coast (Suakin to Ashad)
}

\author{
Atiyat Abdalla Fadoul Nuri'1 , Amna Ahmed Hamid², El Abbas Doka M. Ali ${ }^{3} \&$ Eltegani Mohamed Salih ${ }^{4}$ \\ ${ }^{1}$ Red Sea University. Port Sudan, Sudan \\ ${ }^{2}$ Remote Sensing and Seismology Authority.National Center for Research, Khartoum, Sudan \\ ${ }^{3}$ College of Agricultural Studies.Sudan University of Science and Technology, Khartoum, Sudan \\ ${ }^{4}$ Desertification and Desert Cultivation Studies Institute. University of Khartoum, Khartoum, Sudan \\ Correspondence: Amna Ahmed Hamid, Remote Sensing and Seismology Authority. National Center for \\ Research, Khartoum. E-mail: Atiyatabdalla6@yahoo.com/Amnaah71@gmail.com/adoka21@gmail.com
}

Received: November 21, 2015

Accepted: December 15, 2015 Online Published: February 29, 2016

doi:10.5539/jgg.v8n1p55

URL: http://dx.doi.org/10.5539/jgg.v8n1p55

\begin{abstract}
This study aimed to assess the vegetation cover degradation in the Sudanese Red Sea coast (from Suakin to Ashad) after the drought during the period from 2000 - 2011. Remote Sensing and GIS techniques were used beside field survey to conduct the study. Moderate Resolution Imaging Spectrometer (MODIS) terra 2000 -2001, 2005-2006 and 2010-2011 time-Series images mainly the 16 days Normalized Difference Vegetation Index (NDVI) product and Enhanced Thematic Mapper plus $\left(\mathrm{ETM}^{+)}\right.$images dated 2005 and 2010 were used. Unsupervised classification methods were used to detect vegetation cover of the study area. Based on field survey investigations, beside the data collected on the study area and image interpretation, it was evident that season 2005-2006 and season 2006-2010 are good seasons in the vegetation cover compared to season 2000-2001. Five land cover classes were detected; wet land, bare land and three classes of vegetation cover (dense vegetation, moderately dense vegetation and sparse vegetation cover). Spectral signatures of the three dominant land cover vegetation species were detected. Areas of the three classes of vegetation cover area (dense vegetation, moderately dense vegetation and sparse vegetation cover) were calculated per $\mathrm{km}^{2}$. The study concluded that MODIS could be used as a cost effective tool in assessing land cover changes and monitoring vegetation cover degradation.As well, it could also be used to detect fairly the different vegetation species in arid and semiarid regions.
\end{abstract}

Keywords: Sudanese Red Sea coast, vegetation cover, degradation, remote sensing

\section{Introduction}

Desertification is defined as "Land degradation in arid, semi-arid and dry sub-humid areas resulting from various factors, including climatic variations and human activities" (UNCED, 1992; 1994). There are many processes that lead to desertification; one of them is vegetation degradation.

The study was carried out in Red Sea State, Sudan which lies in a very harsh area suffering from scarce and variable rainfall which may further be subdivided into extreme arid, arid and semi-arid region. The main problem which at focus is the deterioration in the vegetation cover that exposes the soil to wind and water erosion, reduces water conservation and finally encourages migration of inhabitants and their animals to other regions of the state. Ali and Mohammed (1991), reported that the Red Sea state over the last two decades has not only experienced high variability of rainfall but also a decrease both in amount and frequency within this period resulted in a pronounced ecological degradation that is evidently shown in relatively low specific diversity, poor species performance and minimal regenerative capacity of woody and herbaceous species.

Vegetation degradation has resulted from various factors including human induced activities and severe prolonged drought under poor land resource management (Mustafa, 2007). Its assessment and monitoring entails the use of remote sensing data that offers the possibility of gaining environmental data over both large areas and relatively long time-periods. Hence MODIS 16-day NDVI images, $250 \mathrm{~m}$ resolution and Landsat Enhanced Thematic Mapper (ETM) were used in addition to field survey investigations. All data integrated in a GIS to assess the status of vegetation cover in the study area and to achieve the following objectives: 
To assess vegetation degradation along Sudan coast during the period 2000- 2011 using the freely available coarselmoderate resolution data of MODIS.

To classify and map vegetation cover and the dominant species using coarse and medium resolution satellite data.

\section{Study area}

The study was conducted in Red Sea State in an area extending from Suakin to Ashad beyond the Red Sea Coast. The study area lies between longitude $37^{\circ} 19,37^{\circ} 54 \mathrm{E}$ and latitude $18^{\circ} 58,19^{\circ} 14 \mathrm{~N}$ covering an area of 1,700 $\mathrm{km}^{2}$ (Figure 1).
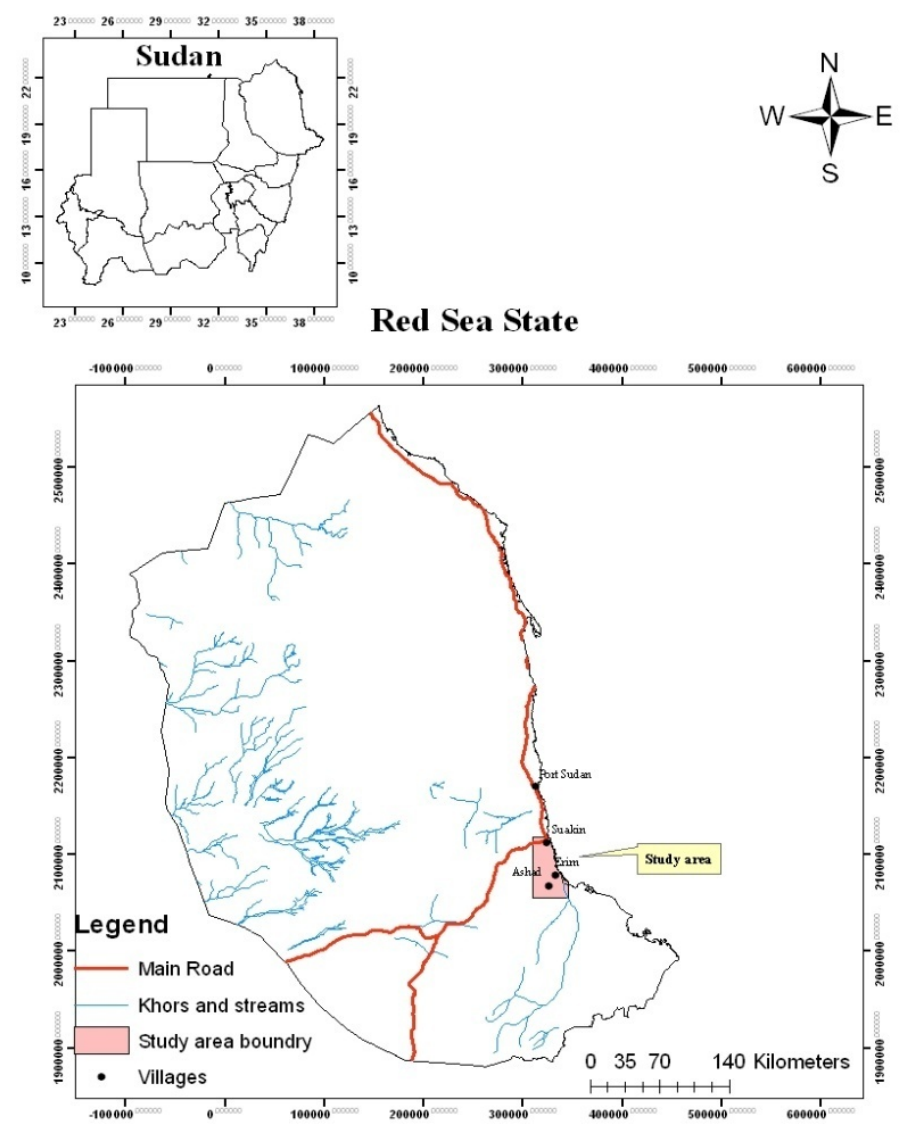

Figure 1. Location of the study area

The state lies in arid and semi-arid zones with a coastal plain extending from the coast to the foot of the Red Sea Hills (20 - $30 \mathrm{~km}$ wide) that includes salt marshes and several inlets which serve as fishing harbors (Marsas) and lagoons. Between the raised coral beach of the coastline and the main plain (desert) there are number of seasonal freshwater streams and deltas, covered by silt, sand and gravel (Babiker, 1991; Abd el Ati, 1996). The saline soils dominate the salt marsh strip of the coast, with a gradient that decreases away from the coast. Seasonal streams (Khors) are the main sources of water in the state (Mohamed, 1999). Along these Khors a numbers of dams were built in Goub and Goubolfor water harvesting (Ministray of Aricultural, 2010)

Kassas (1957) listed seven plant communities within the salt marsh: Avicenna marina, Arthrocnemum glaucum, Halopeplis perfoliata, Aeluropus lagopoides, Sporobolus spicatus, Suaeda monoica and Suaeda fructicosa, community.The Ministry of Agricultural reports in 2010 declared new other dominant species e.g. Prosopis chillensis, Calotropis procera. From the field survey in 2010, three zones were demarcated and the vegetation cover and type within each zone was identified. The first $0-2 \mathrm{~km}$ zone was dominated by Avicenna marina, Arthrocnemum glaucum and Suaeda monoica, the second 2-4 km zone was dominated by Suaeda monoica, and the third 4-8km was dominated by Acacia sp and Prosopis chillensis beside sparse community of Maerua crassifolia, Leptadenia pyrotechnia, Salvadora persica, Capparis desidua, Zizphus Spina-christi, 


\section{Calotropis procera and Balanites aegyptica}

Agricultural lands within the coastal fringe of the Red Sea are very scarce due to environmental constraints such as high salinity levels and low rainfall which is inadequate to support any reliable rain-fed cultivation. However, seasonal cultivation of small holdings is practiced on the catchments areas of seasonal streams (khors). Rain-fed grain such as Dura usually cultivated during extraordinary good rainy seasons within the infrequent surface runoff (Ali and Mohammed, 1991). The field survey 2010 records showed millet cultivation areas in Nulabab, Goub and Haydoob regions.

Animal husbandry consists of goats and cattle and often very rare. Khor Baraka and its delta dominated by camels, goats, sheep, and cattle (Mustafa, 2007). Animals roam around settlements or are herded to various types of range.

\section{Materials and Methods}

Various ecological studies, including that of the polar environment, are now using the remotely sensed NDVI, e.g. MODIS-NDVI as a proxy of vegetation productivity rather than performing direct vegetation (Santin-Janin et al., 2009). The earth science community uses MODIS land products for numerous research applications, which include mapping deforestation, identifying desertification, fire fuel estimation, burn scar identification, ecosystem evolution, invasive species potential, grazing impacts, and crop yield estimation (Van Leeuwen et al., 2006 and Wardlow et al., 2007). MODIS brings potential enhancement to any application where daily regional assessments are necessary to identify significant changes to the land surface that may indicate phenomena related to climate change (Brown et al, 2008). MODIS NDVI 16 day's composite datasets for eight year (2001 to 2008) have been used for the assessment of variations in vegetation cover over the years in space and time in the Kosi river sub-catchments (Alam et al, 2013). It was evident that MODIS NDVI data could be used to provide timely and detailed vegetation status and an input to biophysical, geochemical and climate models that require timely estimation of the forest area (Alam et al, 2013).

Remote sensing data in form of NDVI images created from MODIS-Terra sensor (250m spatial resolution) Images were obtained from (LAADS) and http://www.reverb.Echo.org. Landsat $\mathrm{ETM}^{+}$images obtained from GLCF and USGS visualization viewer web site were used as a main source of data. Secondary data includes climate parameters from Sudan Meteorological Authority. ENVI 4.7 and Arc/GIS 9.3 software were used for data analysis and map generation. MODIS is mainly designed for global change research (Justice et al., 1998). MODIS data are available in standard form, as calibrated radiances. Time-series of MODIS 16-day NDVI images, $250 \mathrm{~m}$ resolution was obtained for 28 August 2000 to 28 August 2001, and the same time series images from 2005 to 2006 and from 2010 to 2011. There were two images per month and a total of twenty-four images. The infrared spectral bands are useful for identifying changes in vegetation because the brighter a pixel is, the greater the amount of photosynthesizing vegetation present. Several ratios of the red and infrared bands of satellite imagery have been created to make use of this relationship (Lyon. et., al, 1998; Jenson, 1996). NDVI is a product based on red and infrared ratio. Because of few classes produced with classification of the NDVI value $(-1-+1)$, before stacking the NDVI value was converted to the range $(-200-+200)$ using the following equation experiment.

$$
\begin{gathered}
\text { [Band Math [round [[100*b1] +100]] } \\
\text { b1 = NIR }
\end{gathered}
$$

The 16-day NDVI were stacked into a 24-band NDVI image. Unsupervised classification (ISODATA in ENVI) was used to classify the MODIS time-series stacked image and generate 24 classes. Use of unsupervised techniques is recommended for large areas that cover a wide and unknown range of vegetation types (Brain, 2007). The initial 24 classes from the unsupervised classification were merged in to a single class and converted to vector layer. The vector layer was used to subset a new region of interest from the same MODIS time-series stacked image which was reclassified using the same ISOCLASS algorithm to generate new 24 classes unless it was possible to identify 6 classes of the vegetation cover. In this study 3 classes of vegetation cover were obtained and mapped. Google earth was used to confirm the detected classes. Class statistic was made for each time - series image to have the accurate classes.

The accurate zones and locations of some vegetation cover species (Suaeda monoica, Avicenna marina and Prosopis chillensis) were detected and recorded by GPS, where 60 observations points were made during 2010 field survey. The Near Infra Red (NIR) pixel value of the dominant species was interpreted and compared using Landsat ETM and MODIS images. This help to detect the specific species zones in different images. 


\section{Results and Discussion}

Land cover maps were produced based on MODIS time - series (2000- 2001, 2005-2006 and 2010-2011). Five land cover classes were identified and mapped; two land-cover classes (wet land and bare land) and three vegetation-cover classes (dense vegetation, moderately dense vegetation and sparse vegetation cover). Figure (2) shows land cover and vegetation density based on MODIS image analysis. From the figure it was clear that season 2005-2006 and season 2010-2011 were good seasons in the vegetation cover compared to season 2000-2001. Figures (3, 4 and 5) show the spectral signature curve of the five land cover classes during 8/2000-8/2001, 8/2005-8/2006 and 8/2010-8/2011 respectively based on MODIS NDVI 16 day images. Wet land always reads low reflectance but from the figures wet land reads high reflectance in few images and this could be explained by the times of the low sea tide when mangrove and other salt marsh vegetation appeared and reflect high reflectance.

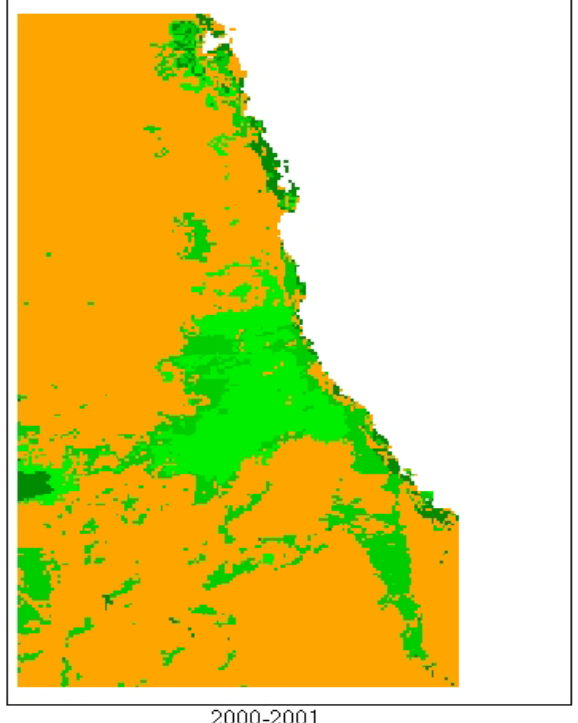

$2000-2001$

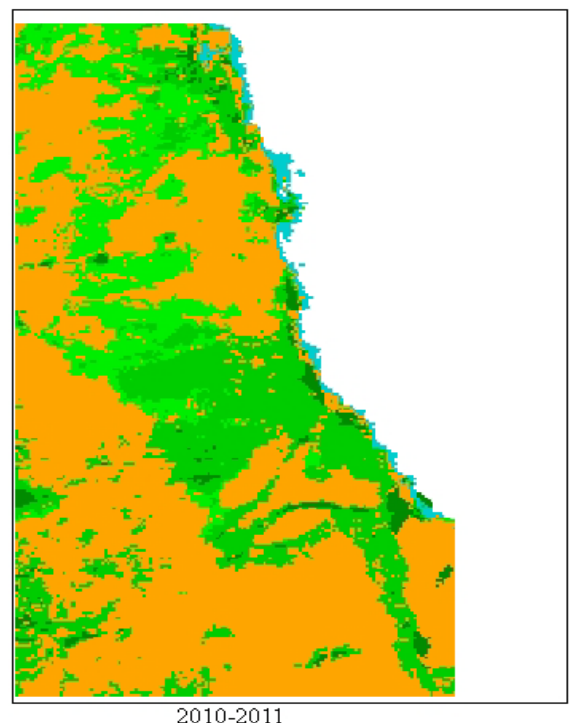

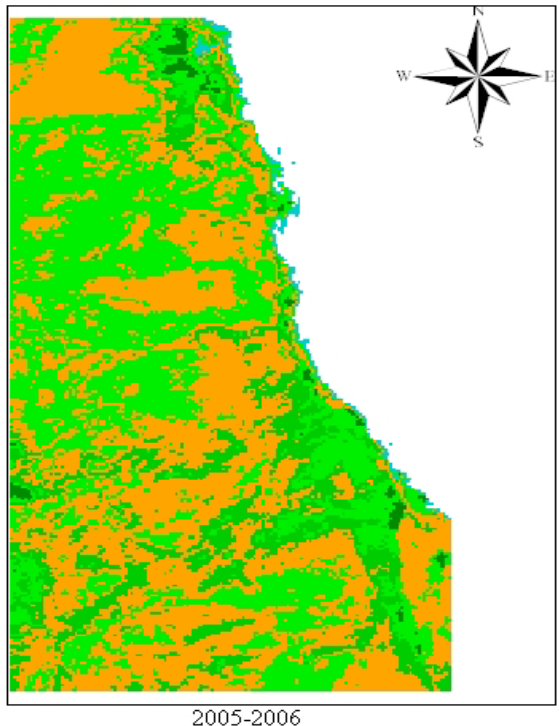

$2005-2006$

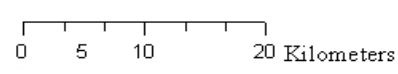

Figure 2. Land cover and vegetation density based on MODIS NDVI 16 days images analysis

In seasons 2000-2001 as seen in images 4 to 11 which are acquired from 15/October to 2/ February/ 2000, there was an increase in vegetation cover reflectance especially in class sparse and moderately dense vegetation. That was due to the rainy season $(150 \mathrm{~mm})$ when there was high rate of annual plant growth and rain fed agriculture which was cultivated from October to February (Local communities' interviews, 2010). Also the annual rainfall 
decreased and reached $50 \mathrm{~mm}$ in season 2005. This explained the approximately equal NDVI value of the three classes: moderately dense vegetation, sparse dense vegetation and bare land in the whole year. Season 2010-2011 showed high reflectance of sparse vegetation in images 5 to 12 which are acquired in period from 31/October to 18/February/2010 during the rainy season and the cultivated period. This was also supported by seed distribution in the area $(2 \mathrm{Kg} /$ feddan in Suakin and Ashad respectively) by Soil Conservation Department (Ministry of Agriculture, 2010).

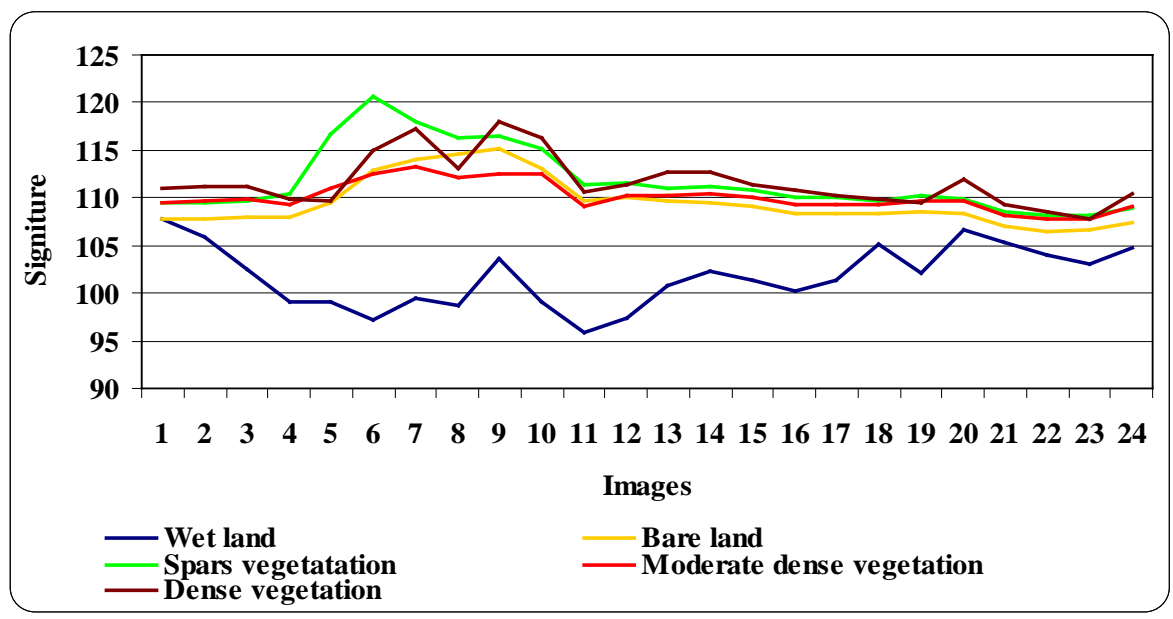

Figure 2. The spectral signature of five land cover classes during 28/8/2000 and 28/8/2001 based on MODIS NDVI 16days images

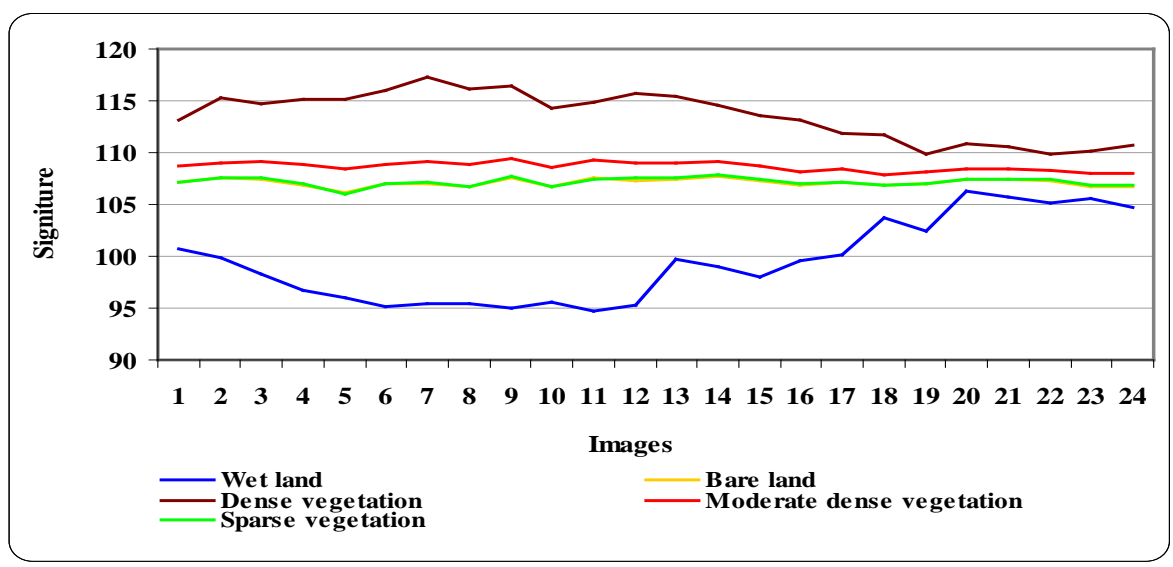

Figure 4. The spectral signature of the five land cover classes during 8/2005 and 8/2006 based on MODIS NDVI 16days images

Table 1. Area of vegetation cover classes per $\mathrm{Km}^{2}$ extracted from NDVI MODIS time series images ISO unsupervised classification

\begin{tabular}{|c|c|c|c|c|}
\hline Image time series & Dense & Moderate & Sparse cover & Total \\
\hline $\mathbf{2 0 0 0 - 2 0 0 1}$ & 34.6 & 183.9 & 161.5 & 380 \\
\hline $\mathbf{2 0 0 5 - 2 0 0 6}$ & 17.2 & 246.6 & 662.9 & 926.7 \\
\hline $\mathbf{2 0 1 0 - 2 0 1 1}$ & 43.3 & 383.2 & 242.2 & 668.7 \\
\hline
\end{tabular}




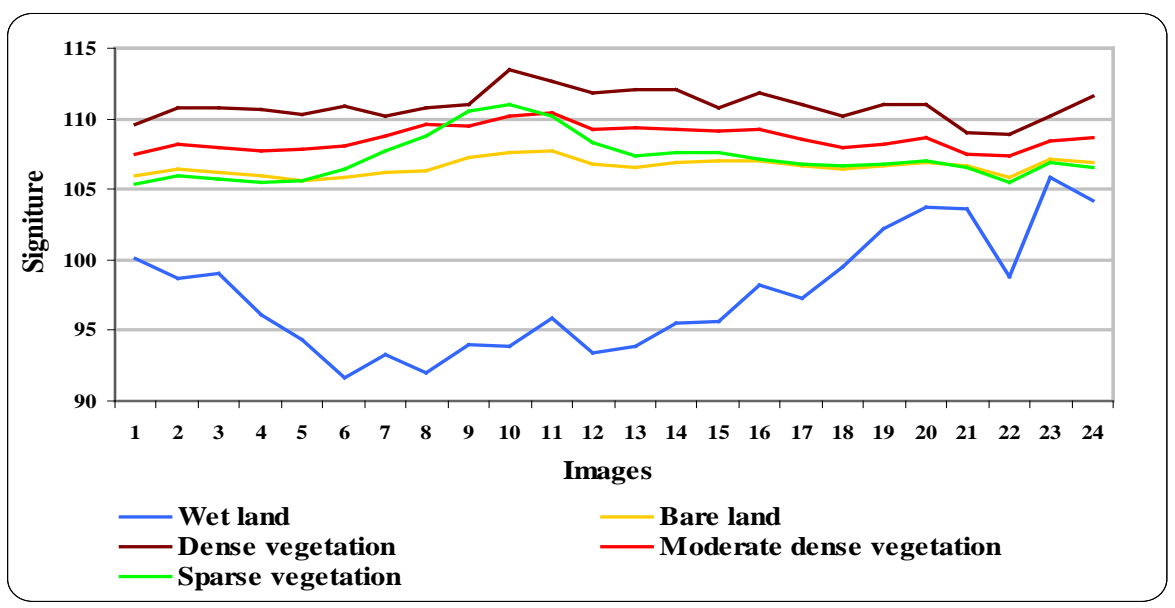

Figure 5. The spectral signature of the five land cover classes during 8/2010 and 8/2011 based on MODIS NDVI 16days images

Tabe1 shows the area per $\mathrm{km}^{2}$ of each class in figure 2. The dense vegetation covers large area in 2000-2001 and 2010-2011 seasons while the spare vegetation covers large area in 2005-2006 season. Also, the moderate vegetation covers large area in 2005-2006 and 2010-2011. The total area increased in 2005-2006 season and decreased in 2010-2011 season.

\section{Comparison of Vegetation Signature between MODIS and ETM Data}

Signature of some vegetation cover was studied in different bands of the two sensors MODIS and ETM. From signature comparison it was clear that the vegetation species can be detected in the low resolution data from MODIS as it is in the moderate resolution data of ETM. Figures (6) and (7) show Mangrove (Avicenna marina) signature assessed in MODIS and Landsat. The NIR (B2 in MODIS and B4 in ETM) pixel value (Digital Number (DN)) ranged between 100 and 150 in both MODIS and ETM.

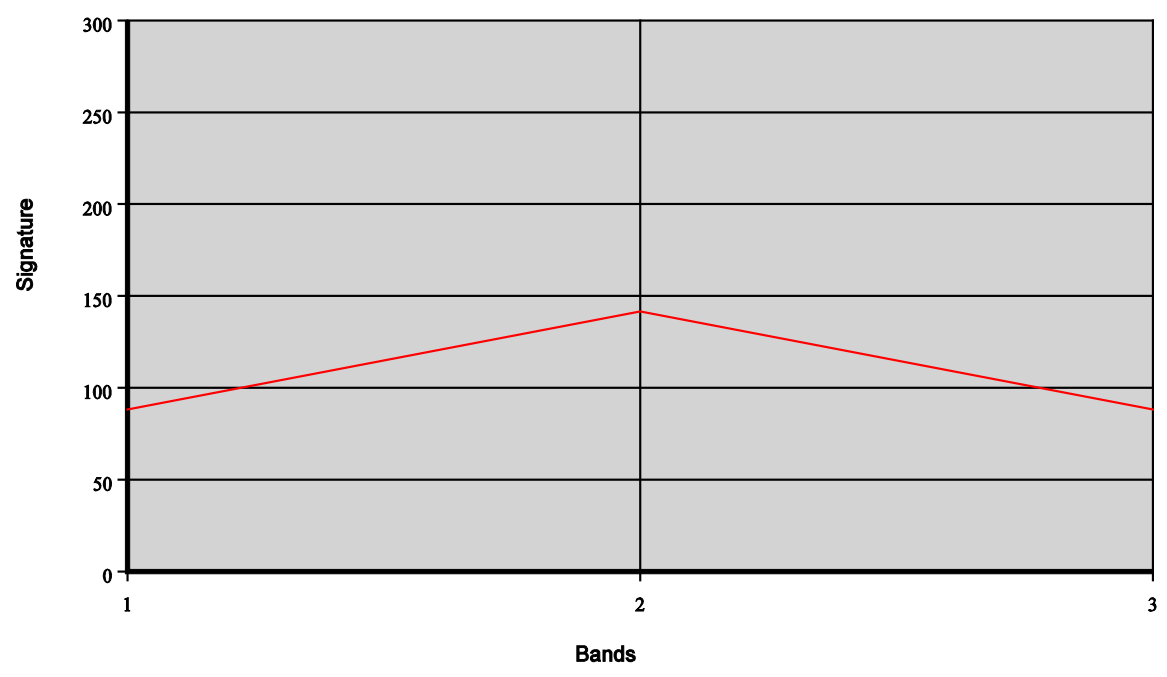

Figure 6. Mangrove (Avicenna marina) signature in MODIS image (NIR =Band2) 


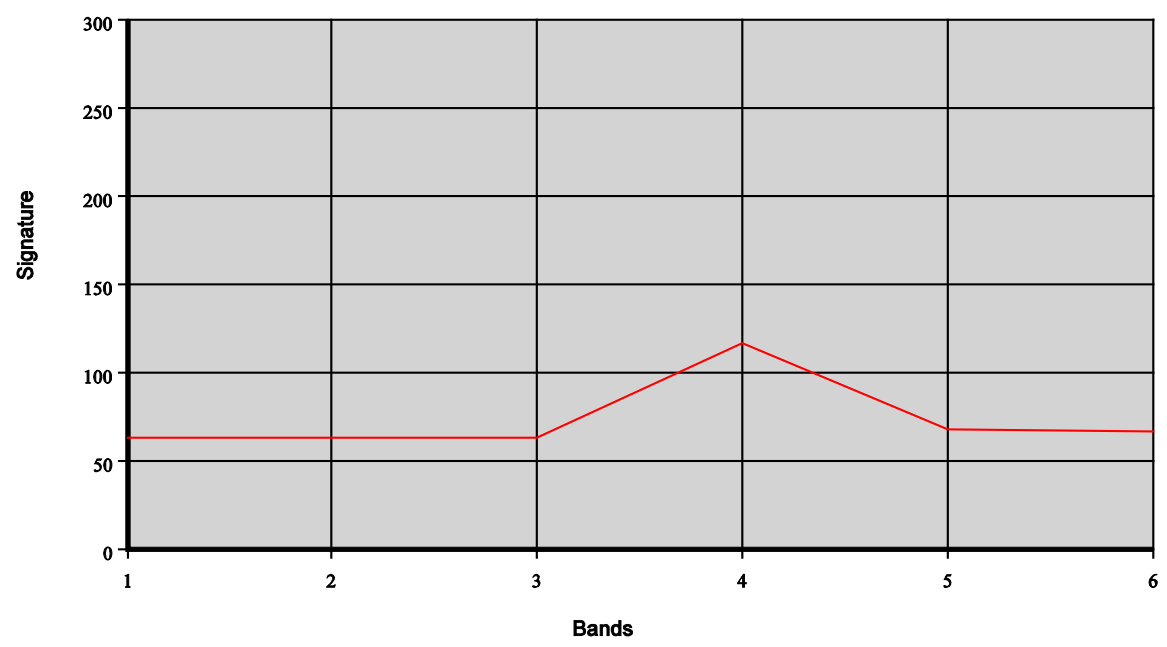

Figure 7. Mangrove (Avicenna marina) signature in Landsat image (NIR =Band4)

Figures (8) and (9) showed Suaeda monoica NIR ( $\mathrm{B}_{2}$ in MODIS and $\mathrm{B}_{4}$ in ETM) signature which ranged between 150 and 200 in the two sensors. Also figures (10) and (11) showed Prosopis chillensis NIR signature. The DN was ranged between 200 and 250 in MODIS and ETM. It was clear that all different species represent approximately the same signature in the two sensors. Prosopis chillensis has the highest reflectance of NIR and Mangrove has the lowest reflectance and this may be due to Mangrove statues which was surrounding by water and mud that influence the reflectance. On the other hand Prosopis chillensis had the highest DN due to its characteristics as an ever green tree as it is a drought resistant species. Also Suaeda monoica is a salt tolerant species. It has water storage leaves which affect NIR reflectance.

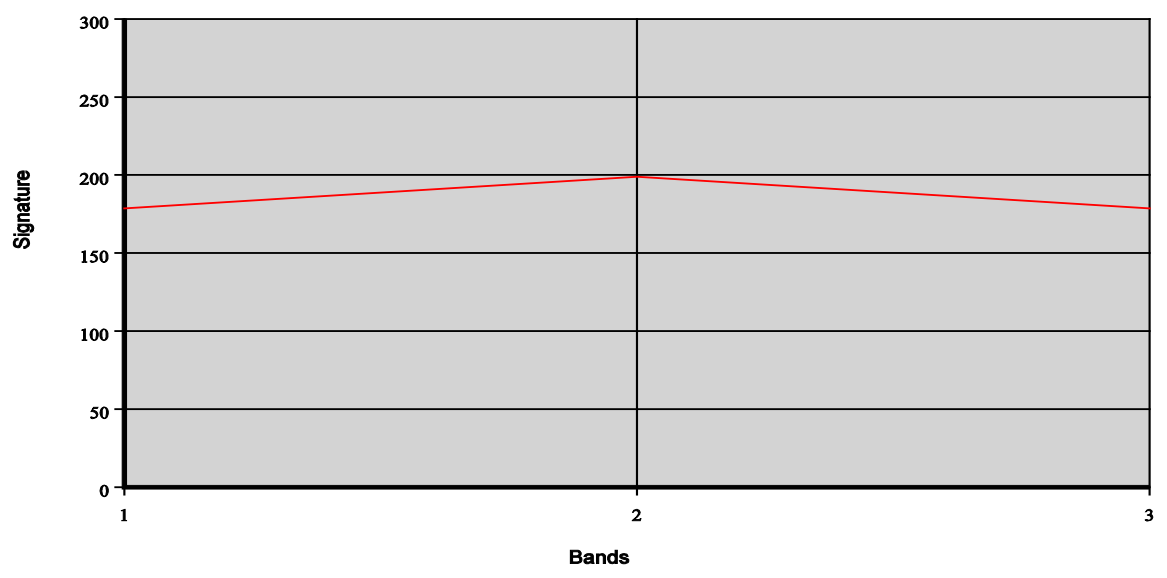

Figure 8. Adalib(Suaeda monoica ) signature in MODIS image (NIR =Band2) 


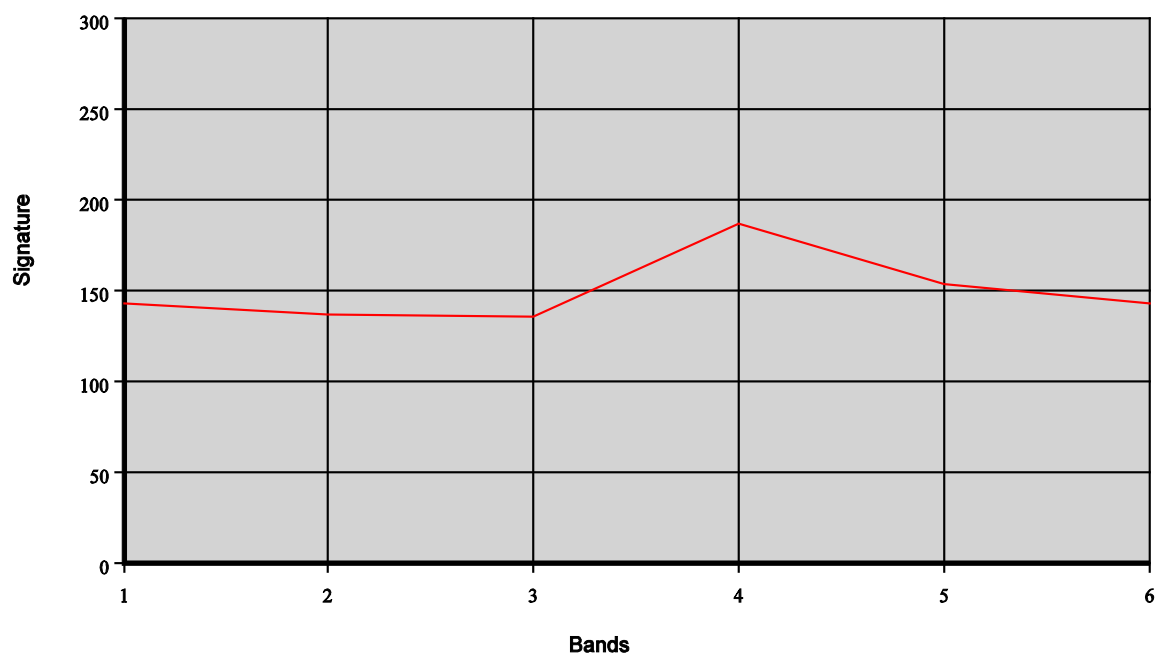

Figure 9. Adalib(Suaeda monoica) signature in Landsat image (NIR =Band4)

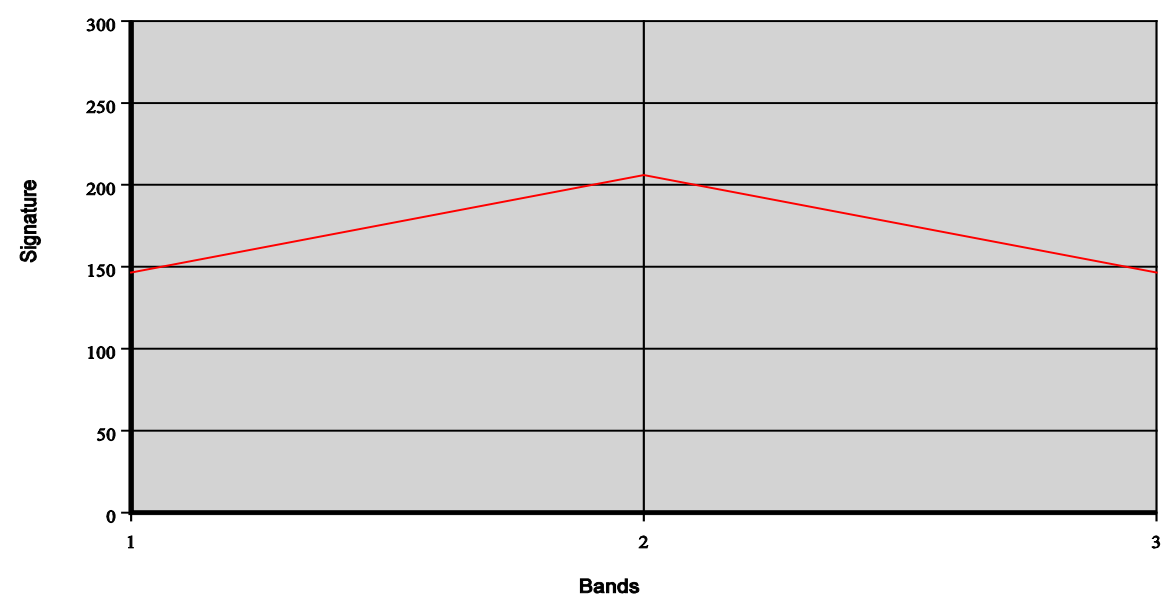

Figure 10. Mesquite (Prosopis chillensis) signature in MODIS image (NIR =Band2)

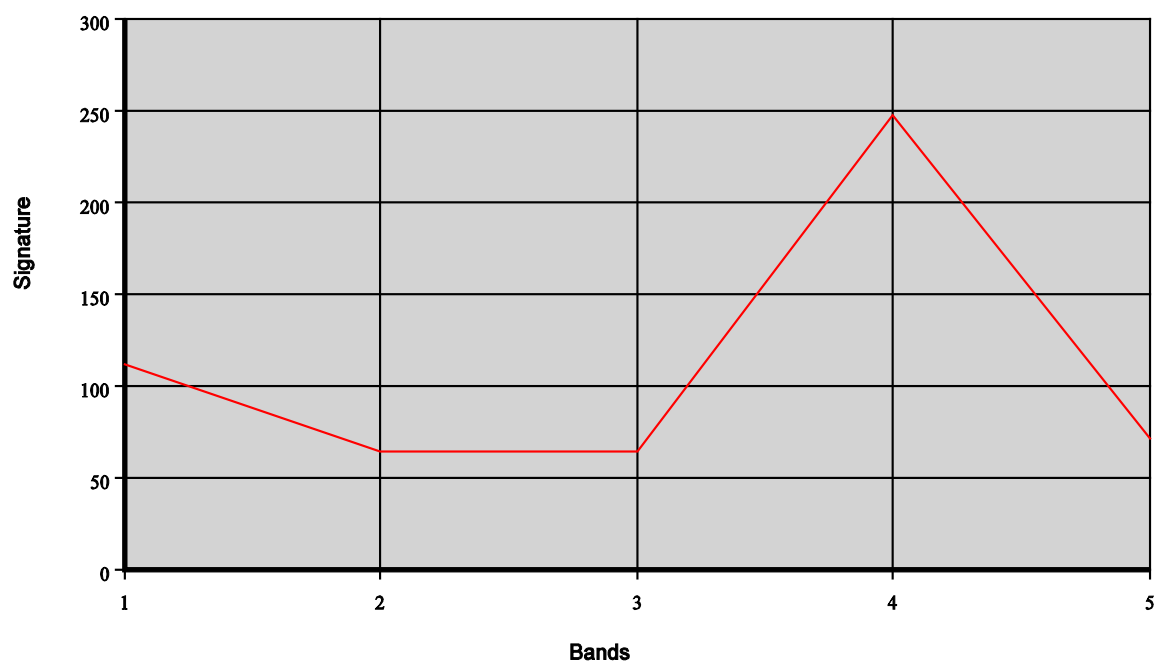

Figure 11. Mesquite (Prosopis chillensis) signature in Landsat image (NIR =Band4)

Vegetation cover interpretation verified that the area under vegetation increased gradually from season 
2000-2001 to season 2005 -2006 and it decreased in season 2010 -2011.The increase in vegetation cover from season 2000-2001 to season 2005 -2006 was due to increase in Prosopis chillensis area around Suakin and khors, and Amyoga seeds dispersion, by soil conservation department - Ministry of Agriculture, in area from Erim to Ashad since 2005. Vegetation signature comparison between MODIS and TM prove that MODIS data could be used to detect fairly the different vegetation species such as Suaeda monoica, Prosopis chillensis and Avicenna marina.

\section{Conclusion and Recommendations}

Based on the study results it could be concluded that MODIS with its high temporal resolution, despite its low spatial resolution could be used as a cost effective tool in monitoring vegetation cover degradation and assessing land cover within the year in different season as compared with Landsat moderate spatial resolution data.

Vegetation signature comparison showed that MODIS data could be used to detect different vegetation species such as Suaeda monoica, Prosopis chillensis and Avicenna marina. This allows MODIS data to be used as an efficient tool for rangeland assessment and monitoring in arid and semiarid areas.

The study recommended implementation of proper programs and plans for management and development of pastures, forests and soil conservation to avoid desertification and land degradation hazards in such fragile systems.

The use of remote sensing and GIS as tools for natural resources assessment and management is recommend, hence capacity building programs in the universities and the concerned ministries should be supported to enable conduction of such studies.

\section{References}

Abd el Ati, L. H., Harir, Sh., Krzywinski, K., \& Vetaas, O. R. (1996). Survival on Meagre Resources. HadendowaPastoalism in the Red Sea Hills. NordiskaAfrikainstitutet, Uppsala.

Alam, M. E., Mallick, J., Bhaskaran, S., Rahman, A., \& Dutta, D. (2013). Spatio temporal assessment of vegetation covers in the upper catchment of Kosi river basin using MODIS data. International Journal of Remote Sensing \& Geoscience (IJRSG), 2(6). ISSN No: 2319-3484.

Ali, A. S., \& Mohamed, B. F. (1991). The ecology of the Red Sea Coast in Sudan. RESAP. Tech. Paper.

Babiker, F. R. (1991). Soils of The Red Sea salt March in Sudan. Some ecological observation. Red Sea Area Program (RESAP). Annual workshop- Sinkat.

Brain, D. W., Stephen, L. E., \& Jude, H. K. (2007). Analysis of time-series MODIS $250 \mathrm{~m}$ vegetation index data for crop classification in the U.S. Central Great Plains. Remote Sensing of Environment, 290-210.

Brown, J., Jenkerson, C., \& Gu, Y. (2008). Using MODIS Vegetation Indices for Operational Drought Monitoring. National Integrated Drought Information System Knowledge Assessment Workshop: Contributions of Satellite Remote Sensing to Drought Monitoring.

Jenson, J. R. (1996). Introductory Digital Image Processing: A Remote Sensing Perspective, $2^{\text {nd }}$ edition. Prentice Hall. New Jersey, 318.

Justice, C. O., Vermote, E., Townshend, J. R. G., Defries, R., Roy, D. P., Hall, D. K., .. Barnsley, M. J. (1998). The Moderate Resolution Imaging Spectroradiometer (MODIS): Land remote sensing for global change research. IEEE Transactions on Geoscience and Remote Sensing, 36, 1228- 1249.

Kassas, M. (1957). On the ecology of the Red Sea coastal land. J. of ecology, 45, 187-203.

Lyon, J. G., Ding, Y., Ross, S. L., \& Chris, D. E. (1998). A change detection experiment using Vegetation Indices. Photogrammetric Engineering and Remote Sensing. 64(2), 143-150.

Ministry of Agriculture. (2010). Annual Report, Ministry of Agriculture, Range Land Management Department. Khartoum, Sudan.

Mohamed, F. B. (1999). National biodiversity strategy and action plan. Diversity in Mangrove and Halophytes, Red Sea. Sudan.

Mustafa, M. A. (2007). Desertification Processes. UNESCO Chair of Desertification. University of Khartoum, 111-128.

Santin-Janin, H., M.Garel, J. L., \& Chapuis, D. P. (2009). Assessing the performance of NDVI as a proxy for plant biomass using non-linear models: a case study on the Kerguelen archipelago, 32(6), 861-871. Springer. 
VanLeeuwen, W. J. D., Orr, B. J., Marsh, S. E., \& Herrmann, S. M. (2006). Multi-sensor NDVI data continuity: Uncertainties and implications for vegetation monitoring applications. Remote Sensing of Environment, 100, 67-81.

Wardlow, B. D., Egbert, S. L., \& Kastens, J. H. (2007). Analysis of time-series: MODIS 250 m vegetation index data for crop classification in the U.S. Central Plains. Remote Sensing of Environment, 108, 290-310.

\section{Copyrights}

Copyright for this article is retained by the author(s), with first publication rights granted to the journal.

This is an open-access article distributed under the terms and conditions of the Creative Commons Attribution license (http://creativecommons.org/licenses/by/3.0/). 